\title{
Can a Home Care Package deliver a meaningful life? Challenges for rural home care delivery
}

\author{
Pauline Marsh*1, Amelie Fuller ${ }^{1}$, Judith Anderson ${ }^{2}$ \\ ${ }^{1}$ Centre for Rural Health, University of Tasmania, Australia \\ ${ }^{2}$ School of Nursing, University of Tasmania, Australia
}

Received: January 5, 2021

DOI: $10.5430 /$ jha.v10n2p12
Accepted: March 8, 2021

URL: https://doi.org/10.5430/jha.v10n2p12

\begin{abstract}
Objective: To explore the capacity and responsiveness of the Home Care Package (HCP) Program to deliver the promise of a meaningful life for rural residents.

Methods: In-depth interviews utilising appreciative enquiry in two local government areas in rural/outer regional Tasmania (MM2-6). Participants: Rural staff and residents who were either receiving, seeking or delivering support through the HCP Program.

Results: Interviews revealed that positive impacts of being assisted to stay at home resulted when staff were able to provide support that was appropriate to need, and enabled the continuation of rural community engagement, individual autonomy and control. When the HCP did not provide these, or even hindered them, there were negative consequences, and feelings of confusion, mistrust, and disappointment for staff and residents. The rural context creates specific challenges for the HCP Program in its current form, related to service availability and choice, staff recruitment, training and availability, and client/provider needs mismatch.

Conclusions: Older rural people are variously impacted upon by the HCP Program. Factors of rurality, including workforce issues, hamper the Program's potential to positively contribute to a meaningful life. As demand grows, changes are needed. There is a need to examine the Program design for urban-centrisms, and gain a greater awareness of older rural people's needs and rural service challenges.
\end{abstract}

Key Words: Age care, Purpose, Significance, Coherence, Place-based

\section{INTRODUCTION}

Living a life that feels meaningful can be challenging to achieve. This is especially so when our work, social and home lives undergo change or disruption, which sometimes occurs as we age and face health challenges. Research has highlighted the important contributions that social contact, meaningful activity and an ongoing preservation of self-identity have in maintaining a meaningful life for older people - particularly for people residing in aged care accom- modation. ${ }^{[1-4]}$ Preventing admission in residential aged care can generally provide an improved sense of health and wellbeing for the person involved, as well as a substantial cost benefit for the government ${ }^{[5-7]}$ Improved health outcomes are predicted for older people if health services are aligned to community-based care. ${ }^{[8]}$ However, the factors that enable a meaningful life for people ageing at home are less well known - and even less is known about older people living at home in rural areas. ${ }^{[9]}$

*Correspondence: Pauline Marsh; Email: Pauline.Marsh@utas.edu.au; Address: Centre for Rural Health, University of Tasmania, Australia. 
This study aims to improve our understanding of if and how the Home Care Package (HCP) Program enables older rural residents to live a meaningful life, and to identify the particular challenges for the rural community aged care workforce delivering this Program.

The HCP Program aims to "help older Australians with complex care needs to live independently in their own homes" for as long as possible. ${ }^{[10]}$ At the time of writing, it provides over 90,000 Australians across rural-urban gradients with access to subsidised health and social services such as nursing, allied health and therapy, assistance in meal preparation and diet, transport and social activities. It is part of the Australian Government Aged Care program which oversees residential and home-based aged care support. Established in 1997, the HCP Program allocates a fixed amount of money per individual, who work with assessment agencies and service providers to organise the most appropriate services for their situation. People are assessed at various levels of need, from 1-4, and funding is matched accordingly. An allocated service provider, not the individual, holds the funds and manages the payments. There are over 900 services providers, a finite number of HCPs, and currently demand is far greater than supply and the waiting list is over 70,000 people. ${ }^{[10]}$

Reviews and evaluations of the Program to date reveal various general challenges and shortcomings common to both urban and rural areas, some of which go beyond problems related to the insufficient number of packages. ${ }^{[7]}$ An internal Department of Health review, ${ }^{[1]}$ for example, reported high levels of overall satisfaction, however notes there is less uptake of services outside of metropolitan areas. Other external reviews identify prolonged waiting times for HCPs correlating with increased mortality rates ${ }^{[12]}$ and perpetuating social inequities ${ }^{[13]}$ across urban and rural gradients. Davis and Bartlett's 2008 review of challenges specific to rural Australian communities included the negative influence of formal service-infrastructure and "urban-centric" views in the aged care system. ${ }^{[9]}$ Given this context, it is reasonable to assume that rural residents have particular challenges related to rurality. It is this issue that we explore in this paper: not by urban/rural comparison, rather through in-depth examination and cross-sectional analysis of the experience of the HCP Program by people living in one small rural setting, and the staff who deliver the Program. Through this prism, we examine what enables or hinders it from achieving its promise to ensure a meaningful life for rural residents.

The idea of a meaningful life is a multidimensional construct, but can be thought of as comprising three broad, abstract facets: purpose, significance and coherence. ${ }^{[14]}$ That is to say, we experience meaningfulness when we have a purpose to living, when we feel our life matters, and when it makes

Published by Sciedu Press sense. A sense of a meaningful life is subjective and contextual, however ${ }^{[15]}$ and is therefore able to be shaped by factors such as rurality and the receipt of care at home. For example, rural disadvantage impacts on community integration and social capital ${ }^{[16]}$ and the community aged care workforce. ${ }^{[17]}$ Rural population ageing is a global phenomenon ${ }^{[18]}$ and of ten associated with a higher vulnerability of elderly people in rural areas, due to gaps in available health and care services, distances to service alternatives and to family caregivers, as well as common economic disadvantages of a rural demographic. ${ }^{[15]}$

Nevertheless, rurality can also positively influence life for older people. ${ }^{[17]}$ Health and aged care services in rural areas rely heavily on informal assistance and volunteer-based programs in meeting distinctive needs ${ }^{[19]}$ For example, Heather Gibb in her case study of a community in remote northern Australia (2018), where aged care services are virtually non-existent, illustrates how volunteer-efforts supplement the gaps in, leading to stronger resilience and community integration. ${ }^{[20]}$ Many studies have highlighted positive outcomes from local voluntarism in community care, supporting place-integration, plurality between and within communities, and the embedding of local values and customs in service delivery. ${ }^{[21]}$

\section{Methods}

This research adopted an appreciative enquiry approach and applied a qualitative method to investigate the experiences of workforce and clients of the HCP Program in rural Tasmania. Although appreciative inquiry aims to see the positives in a situation, it also aims to act as a catalyst for improvement and empowerment. ${ }^{[22]}$ Appreciative enquiry thus allows a focus on positive characteristics, as well as on problems. ${ }^{[22]}$ This was considered important by the researchers, who were keen to acknowledge that the rural ageing story can be a positive one. Rural residents can be resilient and engaged in their communities, and this research aimed to value everyone's experience and opinions.

Ten in-depth, semi-structured interviews were conducted with two stakeholder groups, older community-dwelling residents $(65+)[n=7]$ and HCP service providers [ $n=3]$ living and working in rural Tasmania. Two adjacent local government areas (LGAs) were included, Tasmania's Central Highlands and Derwent Valley. The combined area of 12,074 $\mathrm{km}^{2}$ has a permanent population of 2,130 and 10,424 people, respectively. Both LGAs have particularly high percentages of older people (24.9\% aged 65+ in the Central Highlands; $18.9 \%$ aged $65+$ in the Derwent Valley) indicating a high demand for aged care services both now and in the near future. 
Coupled with this are two pertinent rural health factors: health and medical services are in short supply in rural Tasmania and people's health outcomes are statistically worse than in urban areas. ${ }^{[23]}$ Using the Modified Monash Model of rurality, both local government areas are classified MM6, and the shared service town, New Norfolk, is at the southernmost point and classified MM2. Eligible research participants included residents who were receiving, seeking or delivering support through the HCP system (see Table 1).

Table 1. Participant overview

\begin{tabular}{lll}
\hline $\begin{array}{l}\text { Interview Participant } \\
\text { (pseudonym) }\end{array}$ & $\begin{array}{l}\text { Current HCP Program } \\
\text { Status and/or role }\end{array}$ & $\begin{array}{l}\text { Monash Modified } \\
\text { Classification (clients) }\end{array}$ \\
\hline Robert & $\begin{array}{l}\text { Receiving HCP Level 4 } \\
\text { Waiting for HCP Services } \\
\text { to commence }\end{array}$ & MM4 \\
Elizabeth & $\begin{array}{l}\text { Receiving HCP level 3 } \\
\text { Marilyn }\end{array}$ & MM2 \\
Thomas & $\begin{array}{l}\text { Receiving HCP level 3 } \\
\text { Receiving HCP level 3 }\end{array}$ & MM5 2 \\
Adele & $\begin{array}{l}\text { Eligible HCP, pre- } \\
\text { service commencement }\end{array}$ & MM 5 \\
Bethany & Receiving HCP Level 2 & MM 2 \\
Margaret & Staff: Case worker & \\
Angela & Staff: Management & \\
Melanie & Staff: Carer & \\
Nicole & &
\end{tabular}

Invitation flyers were distributed by the main HCP provider in the areas. Interested participants contacted the researchers by phone or email, and were interviewed by two researchers (authors). The interview prompts were structured to facilitate discussion that might reveal both the strengths and positive experiences of the HCP, as well as the problems and challenges. Participants' ideas for solutions were invited. Ethics approval was obtained from the Social Sciences Human Research Ethics Committee (H0018300).

Thematic analysis followed a systematic process $^{[24]}$ in which two of the researchers independently read and coded transcripts as units of meaning. Next, the two researchers compared coding, clarified individual analyses through mindmapping, discussion and reflection. This process synthesised the meaning codes into three themes, and are presented under these headings: Appropriate supports; Enabling community life; and Keeping control. The results were then considered through the prism of the meaningful life triangulate - purpose, significance and coherence - and the third author added further critique.

\section{RESUlts}

\subsection{Appropriate supports}

Rural participants benefited greatly from the HCP program when services aligned with needs or wants. People expressed relief and appreciation, for example, when they were able to get help to maintain their larger, older homes and gardens:

"I love my garden. My garden is amazing ... I get a lot of pleasure out of it. So certainly, having the garden services has meant a lot to me. The reason I get the domestic services is purely because ... if I do things it means I'm flat on my back for a day or whatever." (Adele)

However, mismatches between perceptions of need and available services were frequently raised by clients and staff. It was more difficult to utilise funds for home modifications, household devices or mobility enhancing appliances than for support services. Clients expressed frustration that providers did not consider essential things such as driveway repairs, washing machines, mobility scooters or reverse-cycle Heat Pumps:

"They think you take your washing down to the river, bring it home and hang it on the line. Because if you can stay at home, you have to have a washing machine." (Margaret)

There was confusion why people were being given, and charged for, services that they did not either need, want or sometimes receive. The high cost of administration fees was raised, as were concerns about how HCP funds were spent in general. Robert's experience exemplifies this:

"I need assistance within the house, but I can look after my own medication ... I think they charged something like $\$ 75$ an hour, right? ... [The Registered Nurse] called in a couple times to check my medication. She didn't have to, because the report said I was able to look after my own. She just came in and said 'Everything go, okay?' and she did that on two occasions that next month. Just the first time she looked in the chest where the medicines are. Then she went on leave, on holidays. I still got charged a registered nurse, $\$ 47.50$ for calling in every week.” (Robert)

For staff, there was uncertainty and frustration over the regulations and process of approval for HCP services. This was made more confusing in the rural context where community care and primary health care workers provide the various services. Staff described funding for modifications and equipment as a "grey area", and each request was subject to proof that it impacted health and wellbeing directly. This was, however, a subjective understanding of health which exacerbated the mismatch between need and service provision: "I mean, even the simplest things aren't clear. Like food. I know it [the legislation] says 'You can't buy people food unless they're on an [enteral] feeding program or something like that ... but meals on wheels advertise that you can pay through your homecare package... We will pay $50 \%$ of the meals on wheels which is the preparation and delivery'. Not 
the food. But that's the grey area that you drive the truck through." (Angela)

On occasion, staff found that the confusion around what the HCP could provide gave rise to tensions:

"I just think of one lady that, has got, quite significant mental health concerns and she actually will say, no, 'I don't have any mental health conditions at all ... I want to spend my money being taken to church'. So she has a house that badly needs quite a lot of domestic assistance. She doesn't cook, she doesn't cook well for herself, so her self-care is not great. But that's what she wants to do. So, she's a perfect example of how it doesn't fit, you know, because the care needs versus the clinical needs." (Melanie)

People reported a shortage of staff and contractors who were willing to travel to areas outside of the service town, New Norfolk, to provide services. Despite a service provider being located within $20 \mathrm{kms}$ of his home, the only one willing to provide staff to travel to Thomas' house is located 100km away. Consequently his cleaning and transport services incur large added expenses for travel costs, which he felt were not adequately covered:

"[Provider $x$ ] said 'Where do you live?' and I said [location $x]$ and they said 'Oh, we won't come up there we only go $15 \mathrm{kms}$ out of town'. And that's the response I got from everywhere. So, in other words, I gave it away until they knocked on the door. I think I get an extra probably $\$ 70$ because of where I live. Well that's ridiculous... When it costs hundreds to get up here." (Thomas)

"Furthermore, inadequate compensation for travel costs and reluctance to use their own car was thought to deter new staff: 'and I can understand that because it kills your cars.", (Nicole)

Inadequate training of staff and low levels of health literacy in the community were also raised as barriers to being able to provide appropriate supports in the rural area. The HCP was felt to be particularly inadequate to meet mental health needs:

"So what I find the main issues are with people is that [mental illness] is not a diagnosis that is included on an ACAT, because when you're over 65, no one's looking for your mental health. They're looking for dementia and can you shower yourself and can you cook food and how do you do the shopping." (Angela)

Many client participants resourcefully combined formal and informal supports to get the help they needed and wanted. Reasons given for choosing private paid or volunteer services, over HCP-provided ones, included things such as a better match of cost for service, higher quality service, more flexibility, and being with people they had known for a long time. Elizabeth, for example, described the private garden maintenance service she uses:

"They're good guys. They work for it and they don't stop. They don't sit around drinking coffee or smoking or anything. They just go hammer and tongs.” (Elizabeth)

"Sometimes, clients made complaints about their HCP services. On occasion they experienced no change as a result, and even felt worse off for the trouble: 'I don't do stress too well these days, I've found.'” (Adele)

One staff member suggested that HCP problems are almost unsolvable, due to the fact that the Program is designed for urban areas, and cannot be translated successfully into a rural setting:

"I don't think there's an adequate recognition that the needs in that rural space are quite unique and really different." (Melanie)

\subsection{Enabling community life}

Continuing an active community life was seen to be very important. Clients described how neighbours and friends living nearby provided them with a sense of familiarity and safety, as well as opportunities to help each other. Both the home space and the surrounding area beyond the home were important for maintaining social connections:

"Yes, I suppose I could have moved after my husband died ... And I thought, I know all my neighbors and I like living here ... People are friendly and I am never sort of frightened just being by myself, or anything like that. It feels nice." (Margaret)

Participants expressed grief over losing their ability to drive a car in order to see family and friends, or to do activities outside of their homes. Although available, HCP transport was considered to be for practical purposes only, not for the enjoyment of an outing:

"[Organisation $x]$ gives me a free taxi to go to all my medical things, so that's good. But you basically go there and see the doctor and come home. That's not a shopping trip. You get so out of touch." (Marilyn)

Transport was expensive: 'It was costing us roughly - well, $\$ 150$ a day. That's $\$ 300$ a week' (Robert). To get around this, and the inflexibility and the practical imperatives, people made private arrangements:

"The package covers ... a trip to Hobart once a month to get my hair done, [then] I come home with my son. So the reason I get them to drive me to Hobart once a month is so that I come home with my son and he takes me out to dinner 


\section{beforehand." (Adele)}

Information about which community activities were available through the HCP system was unclear, and people were unsure about their entitlements. This was not helped in instances where there was poor communication between service provider and client:

"So I rang up [the woman] in the office because I thought about going to the exercise class they have ... and she immediately said, 'you don't want to go to that, you have to go to the rural health thing.' And I don't know why that was. Nobody has managed to explain it to me yet... I asked was I supposed to enrol or just turn up or what, you know, and nobody knew. So it's a bit confusing." (Marilyn)

Visits from formal carers provided company, friendship, and a "safety mechanism", particularly in situations where clients lived with family members who had drug dependencies or mental ill health. However, providing services in violent or potentially dangerous homes unleashed "ethical minefields", and concerns for staff:

"I've really got to look after the workers as well, you know. If they don't want to go to a place, there's got to be a reason." (Nicole)

\subsection{Keeping control}

To stay at home was a way to maintain freedom, which many people valued highly. The fear of losing autonomy was apparent; whether due to either cognitive decline or other people deeming them uncapable of making their own decisions:

“Well, I won't go to a home. I mean I'll go fishing one day and won't come back. I won't go to a home. No way. I've seen, I've seen them and you know, it's just horrible... Well, compared to here, I mean I've got all the freedom. And I'm used to it, you know, I'm doing my own thing and have done so for 30 years on my own ... I mean, I don't mind people being a passenger on the train, but I like to drive the train myself, you know what I mean?" (Thomas)

In these instances, early application for the HCP, when people had only mild physical or cognitive challenges, provided the means to a stable life at home. For those reluctant to be a "burden" on family, like Adele, the HCP support allowed them to have a choice over who cared for them. She did not see this as handing over her right to independence:

"I live in my own home, I say who can come in to my home. People just don't presume they can send me emails saying 'We will be at your home' because I reply saying, 'Oh no you won't.", (Adele)

However, some clients reported they had no choice of 16 provider, and no control over the costs of the services. Clients on HCPs felt their autonomy was undermined by poor information, confusing paperwork, inadequate communication from providers and a disconnection from their own package:

"I don't agree with the often-touted 'self-managed package' scenario, because they're not, if they were, I'd manage my own money'," (Adele)

For others, the invoicing system was baffling:

"The accounts, the way they take the accounts, is horrendous ... I mean, I know what an account (is), and if you do a statement what it should say. It should say what it's for... People that are older than me that haven't got all their faculties properly and all that and they don't understand, they just go along with it because they don't understand it." (Thomas)

Clients expressed disappointment and frustration at not having access to a "real person" to answer their questions about the HCP. Online-tools and the My Aged Care platform were thought to be particularly difficult, especially for those with poor computer literacy or no access to a computer or the internet. Some found themselves in an unwanted relationship of dependency on their home care provider as a result.

"People expressed feelings of mistrust, being disrespected, and sometimes even a fear of speaking up not wanting to compromise their situation with the only provider to the area where they lived: 'Just because you're an old person, there's some problems with you, they think: well, we'll write them off.", (Robert)

\section{DISCUSSION}

As highlighted early in this paper the HCP Program can assist older people to remain in their own homes and improve their sense of having a meaningful life. Martela and Steger's ${ }^{[14]}$ three key contributors to a meaningful life - purpose, significance and coherence - are accepted as having a significant impact on a person's health ${ }^{[8]}$ and thereby impact on the health care being provided to people. ${ }^{[25]}$ For this reason the themes identified in this study were explored in the context of purpose, significance and coherence for rural ageing and the HCP Program and implications for staff.

\subsection{Purpose}

These results show that receipt of a HCP can sometimes facilitate a sense of purpose - or having a "sense of core goals, aims and direction in life". ${ }^{[14]}$ This was noticeable under the theme of "appropriate supports" where the HCP provided gardening services or transport. Immediate, achievable goals were particularly accessible, like those associated with the physical or cognitive challenges of ageing such as remaining living at home and not in residential aged care, 
continuing to live in a rural area, or minimising reliance on family or friends. Participants' desire to live an autonomous life was sometimes achieved. Many participants who had lost their partners wanted to remain living in the house they had shared, with the memories and connections to their loved ones. Similarly, people who wanted to stay connected with neighbours and involved in social activities were facilitated to do so by access to certain services. Rural areas often feature older homes and larger gardens, with greater demand for maintenance. Receiving help to do tasks that were too difficult were sometimes well facilitated by the HCP and this finding was also supported by international literature. ${ }^{[26]}$

However, accessing the HCP Program does not guarantee that individual goals or aims will be realized. In this study, the theme of "appropriate supports" identified that sometimes the Program even hindered people's goals, or significantly changed the direction of people's lives.

One key reason for this was that clients' perceptions of their own needs could not be accommodated by the HCP Program. For example, people who wanted help to repair septic systems, to live without the internet or mobile phones, or to have no contact with neighbours or family were less well served by the HCP Program than those who required vacuuming help. Although the Charter of Aged Care Rights states that clients should have control over and make choices about [their] care, and personal and social life, including where the choices involve personal risk ${ }^{\text {,27] }}$ when people felt they were novices, in an overly complex system, they were unable to exercise control. This inability to exercise control was improved by staff who identified ways around funding requirements, but were not always enabled to find outcomes to address all of the needs of their clients.

Several rurality factors contribute to a mismatch of needs and services, itself a barrier to achieving goals. The lack of available, suitably trained staff living locally places significant stresses on the community workforce. ${ }^{[11]}$ A general lack of formal regional service infrastructure hampered the capacity for clients and providers to match goals with outcomes. Services that will not travel to areas outside of major cities or regional towns - even $15 \mathrm{kms}$ away - and the prohibitive costs meant travel was limited and particularly for purposes of enjoyment or social connection. Logistical barriers like this indicate a urban-centric design, which fails to adequately take into account rural circumstances. ${ }^{[9]}$

Attitudes and values of staff can sometimes act as barriers, when they are impacted upon by systemic constraints. Both clients and staff wanted to be able to better match needs with services but felt restricted to improve things. Some people were not prepared to tolerate what they considered to be poor

Published by Sciedu Press quality work or care - even though the costs were covered by their HCP. Very highly educated clients were sometimes unable to understand their rights or entitlements. Clients and staff were aware of this, and voiced concerns about people with cognitive impairment challenges or poor health literacy trying to understand the system.

Despite the best of intentions, negative experiences of the HCP sometimes result in discordance between clients and providers. When there is dependency on external agencies, feelings of mistrust, disappointment and frustration amongst clients and staff there exists the opposite of purpose - aimlessness and lack of direction. ${ }^{[14]}$ To a certain degree, people adjusted their aims and goals to match the capacity of the HCP Program. While some felt they had no other option, putting the inconveniences down to life in a rural area, some tried to contest decisions and processes. Where able, these people bypassed the HCP Program. It is these mitigating measures that enable people to maintain a sense of purpose in their lives, in spite of a periodically uncompromising system.

\subsection{Significance}

Our findings support the claim that the HCP Program helps people to remain living at home, even in service-limited ruralareas. When we consider this through the lens of the second of Martela and Steger's three facets of meaning, significance, we can appreciate how this achievement contributes toward a meaningful life. Significance, or "a sense of life's inherent value and having a life worth living",[14] can be greatly influenced by the home space. Indeed, the home can be considered an extension of our own identity. ${ }^{[28]}$ Moreover, living amongst things that are valued for their personal meaning and for their representations of "homeliness" brings richness to people's lives. ${ }^{[29]}$ In addition, according to Rubinstein and Parmelee ${ }^{[28]}$ attachment to the home does more than just keep "the past alive", it also protects "the self against deleterious change".

Older people commonly make adaptations to their physical home environment, as ageing may require of them. ${ }^{[30]}$ Home modifications funded through the HCP can assist with this function, and participants in this study noted the increased sense of safety they felt, moving about in their home once handrails and raised garden beds for example were installed as was noted in the theme of "appropriate supports". Many older people identify the tasks they are still able to perform themselves, while adapting their ways of doing other activities suiting their changing abilities. ${ }^{[31]}$ However, while some age-related modifications were easy to obtain, requests were also rejected - especially those that were determined to fall outside of the guidelines for "health-specific" devices and modifications. Approvals matched obvious health needs, 
when health is considered through a bio-medical lens rather than a broader understanding of health as wellbeing. ${ }^{[32]}$ With over $\$ 900$ million AUD of unspent funds accumulated ${ }^{[33]}$ the rejection of requests appears unwarranted but was often outside the realm of the local providers. There were unwelcome practical impacts from rejected requests, and also impacts that were psychological and emotional. When the guidelines were unclear, having someone in an external agency seemingly subjectively decide what is important to your life, and what is unimportant, carried a judgement about the value of a person's life, home, needs, and capacity to accommodate the challenges of ageing.

Remaining living at home can facilitate independence - especially important when getting older can sometimes make people feel useless or worthless. ${ }^{[31]}$ In this study, there were people who maintained control over their own home spaces, deciding who entered and when, and what it was that staff did when they were there. However, others experienced a lack of control and a sense of reduced independence. Barret et al. ${ }^{[28]}$ caution against assuming that just because individuals remain in their homes they automatically retain the power to "control and direct their lives" once they start receiving care. They argue that receiving care to continue living at home can even heighten people's sense of disconnectedness from their homes and themselves.

The other way that remaining at home in a rural area can enhance a sense of significance is because it fosters the resilience that is developed through remote living. ${ }^{[20]}$ Rural disadvantage can be mitigated for older people by a strong sense of community and high levels of social capital. ${ }^{[16]}$ Furthermore, withdrawing - spatially and socially - is not always a sign of an unwelcome isolation, it can also be a voluntary act of "selective intensification of involvement". [34] In this study, this was seen to a large extent in the theme "enabling community life" where participants spoke of their longstanding engagement with a community they felt was supportive and added meaning to their lives. Consequently, home and neighbourhoods become even more valuable and significant in older age ${ }^{[35]}$ and the intensely relational nature of home-based caring ${ }^{[3,28]}$ might be all the more meaningful as a result. The participants in this study confirmed the role that staff providing the HCP played and the benefits of them being sensitized to the needs of their clients to have a sense of their significance within that community.

\subsection{Coherence}

People will generally re-negotiate their relationship to the world around them through the process of ageing. ${ }^{[21]}$ Applying the third factor in the triangular framework, the extent to which this re-negotiation might disrupt a meaningful life might depend on the degree to which life stops making sense as a result. In this study, whether a HCP meant people could maintain a sense of comprehensibility, or whether life became uncertain or incomprehensible ${ }^{[14]}$ varied across different situations. Entering into a home care system generally necessitates some degree of place-integration ${ }^{[21]}$ where people re-integrate themselves into a place in a meaningful way, through adjustment and adaptation. Receipt of care can necessitate an identity adjustment also, from independent person to care recipient. ${ }^{[36]}$ Consistent with other studies in the HCP context ${ }^{[37,38]}$ some participants found decisionmaking processes inconsistent, outcomes unpredictable, and information incomprehensible, to a large extent this was seen in the theme "keeping control".

Some clients and staff went to great lengths to understand the HCP system. Family members, lawyers, ombudsmen and advocates had been engaged to help clarify documents and bills. Others disengaged and gave up trying to make sense of the processes. These experiences frequently led to detachment from the system, its outcomes and its aims. Similarly, Ottmann and Mohebbi ${ }^{[39]}$ found a large proportion of HCP receivers wished to have a greater say and more direct access to care. Power was limited by the complexity of a system that did not speak to them, burdened providers and recipients with immense bureaucratic challenges, and was exacerbated by the structural constraints of a rural location. The pressures on a rural workforce ${ }^{[6]}$ may also contribute in part to a component of this confusion through poor communication.

Little time for spending understanding the system, explaining it, or advocating on behalf of clients cannot help. However, the tensions between a market-based system and the principles of consumer driven care ${ }^{[13]}$ might also lie at the heart of what seems to be a deep systemic problem. Regardless, to promote comprehensibility, ways to enhance dialogue between policy makers, home care providers, staff and clients need to be sought. The HCP Program would benefit from a review informed by client and rural aged care workforce input. The experiences of rural clients need to inform policy and practice, factors that create confusion or inconsistencies need to be addressed, and priority given to those that facilitate meaningfulness.

\section{Conclusion}

This study shows how the HCP Program can help people to live at home in rural areas, but that it variously effects people's capacity to live a meaningful life in that home. A HCP sometimes enabled people to pursue their personal goals, nurture the things they value, and make sense of their lives - but not consistently. The rural location created significant challenges for HCP service providers: limited service op- 
tions, staff shortages and insufficient resources provided to frontline staff impact directly on service appropriateness, capacity for client choice and autonomy. These practical concerns in turn shaped emotional and psychological factors for participants, of a sense of purpose, significance and coherence.

This result speaks to a need for future research that critically examines the design of the HCP Program for bias toward urban populations, in order to provide guidance for funding and delivery changes that more adequately account for local and rural circumstances.

Our study also reveals how the meaning of the home is intrinsically bound with the meaningfulness of life itself, and that when practices within the home - including practices of care - devalue the home environment they also devalue one's sense of self. This is an important unintended negative consequence of the current HCP program that requires attention. Further research is needed to assist the HCP Program services to understand and accommodate the interrelatedness between practices of care and sense of self, in order to positively contribute to meaningful lives. Further, to create pathways for elderly people to maintain control and independence over their care services requires accessible navigation of the system. As this study has shown, issues of communication and understanding were some of the main reasons why clients experienced an incoherence in their lives - it does not always make sense. Staff also found aspects of the program inconsistent and over-complicated, and they too experienced a lack of agency or purpose. We found that life lost meaning when people had negative experiences with the HCP Program. Future research into the means for improvement in communication is vital.

At the time of writing, the HCP Program faces new challenges arising from the Covid19 pandemic. It is unknown what future challenges might result of this for rural older people, current service models, and the rural workforce. We can be sure, however, that demand for home-based services will continue to increase, and add new pressures on the rural workforce. Systemic changes are required; and now is our chance to make meaningful improvements.

\section{CONFLiCTS OF INTEREST Disclosure}

The authors declare they have no conflicts of interest.

\section{REFERENCES}

[1] Cutchin MP. The process of mediated aging-in-place: a theoretically and empirically based model. Soc Sci Med. 2003; 57: 1077-90. https ://doi .org/10.1016/s0277-9536(02) 00486-0

[2] James I, Blomberg K, Kihlgren A. A meaningful daily life in nursing homes - a place of shelter and a space of freedom: a participatory appreciative action reflection study. BMC Nurs. 2014; 13: 19. PMid: 25050083. https://doi.org/10.1186/1472-6955-13-19

[3] Kihlgren A. A Meaningful Life for Older Persons Receiving Municipal Care-Unit Leaders' Perspectives. Open J Nurs. 2015; 05: 1233-41. https://doi.org/10.4236/ojn.2015.511110

[4] Australian Government. Guidance and Resources for Providers to support the Aged Care Quality Standards. Canberra: Aged Care Quality and Safety Commission. 2018.

[5] Australian Government. Australia's Health 2016. Australaia's health series. 2016.

[6] Prgomet M, Douglas HE, Tariq A, et al. The Work of Front Line Community Aged Care Staff and the Impact of a Changing Policy Landscape and Consumer-Directed Care. Br J Soc Work. 2017; 47: 106-24. https://doi.org/10.1093/bjsw/bcw112

[7] Palesy D, Jakimowicz S, Saunders C, et al. Home care in Australia: an integrative review. Home Health Care Serv Q. 2018; 37: 113-39. PMid: 29424658. https ://doi .org/10.1080/01621424. 2018. 1438952

[8] Mann J, Quigley R, Harvey D, et al. OPEN ARCH: integrated care at the primary-secondary interface for the community-dwelling older person with complex needs. Aust J Prim Health. 2020; 26: 104-8. PMid: 32290951. https ://doi.org/10.1071/PY19184

[9] Davis S, Bartlett H. Review Article: Healthy ageing in rural Australia: Issues and challenges. Australas J Ageing. 2008; 27: 56-
60. PMid: 18713193. https://doi.org/10.1111/j.1741-661 2.2008.00296.x

[10] Australian Government Department of Health. About the Home Care Packages Program. 2017.

[11] Australian Government Department of Health. Healthdirect Australia: Home Care Package Research. 2018.

[12] Visvanathan R, Amare AT, Wesselingh S, et al. Prolonged Wait Time Prior to Entry to Home Care Packages Increases the Risk of Mortality and Transition to Permanent Residential Aged Care Services: Findings from the Registry of Older South Australians (ROSA). J Nutr Health Aging. 2019; 23: 271-80. PMid: 30820516. https://doi .org/10.1007/s12603-018-1145-y

[13] Fine M, Davidson B. The marketization of care: Global challenges and national responses in Australia. Curr Sociol. 2018; 66: 503-16. https ://doi .org/10.1177/0011392118765281

[14] Martela F, Steger MF. The three meanings of meaning in life: Distinguishing coherence, purpose, and significance. J Posit Psychol. 2016; 11: 531-45. https ://doi .org/10.1080/17439760.2015.1137 623

[15] Penning M, Cloutier D. Long-term care service delivery challenges for ageing place in rural communities. In: Skinner M, Hanlon N, editors. Ageing Resour. Communities- New Front. Rural Popul. Chang. Dev. Volunt., London: Routledge; 2016. 89-102 p.

[16] Winterton R, Warburton J. Does place matter? Reviewing the experience of disadvantage for older people in rural Australia. Rural Soc. 2011; 20: 187-97. https://doi.org/10.5172/rsj.20.2.187

[17] Savy P, Warburton J, Hodgkin S. Challenges to the provision of community aged care services across rural Australia: perceptions of service managers. Rural Remote Health. 2017; 17: 4059. PMid: 28564547. https://doi.org/10.22605/RRH4059 
[18] Andrews GR. Demographic and health issues in rural aging: a global perspective. J Rural Health Off J Am Rural Health Assoc Natl Rural Health Care Assoc. 2001; 17: 323-7. PMid: 12071554. https://doi.org/10.1111/j.1748-0361.2001.tb00281.x

[19] Skinner M, Hanlon N, editors. Ageing Resource Communities - New frontiers of rural population change,community development and voluntarism. London: Routledge; 2016. https ://doi .org/10.4 324/9781315728209

[20] Gibb H. Determinants of resilience for people ageing in remote places: a case study in northern Australia. Int J Ageing Later Life. 2018; 11(2): 1-25. https://doi.org/10.3384/ijal.1652-867 $0.17-333$

[21] Cutchin M. Place Integration: notes on a Deweyan framework for community inquiry. In: Skinner M, Hanlon N, editors. Ageing Resour. Communitites New Front. Rural Popul. Chanve Community Dev. Volunt., London: Routledge; 2016. 24-37 p.

[22] Moore M. Appreciative inquiry: The why: The what? The how? Pract Dev Health Care 2008; 7: 214-20. https ://doi .org/10.1 002/pdh. 270

[23] Tasmanian Government, Department Health and Human Services. State of Public Health. 2013.

[24] Moustakas C. Phenomenological research methods. Thousand Oaks, California; 2021.

[25] Haugan G, Kuven BM, Eide WM, et al. Nurse-patient interaction and self-transcendence: assets for a meaningful life in nursing home residents? BMC Geriatr. 2020; 20: 168. PMid: 32381032 https://doi.org/10.1186/s12877-020-01555-2

[26] Ohta R, Ryu Y, Kitayuguchi J, et al. Challenges and solutions in the continuity of home care for rural older people: A thematic analysis. Home Health Care Serv Q. 2020; 39: 126-39. PMid: 32174235. https://doi.org/10.1080/01621424.2020.1739185

[27] Australian Government Department of Health. Charter of Aged Care Rights. 2019.

[28] Barrett P, Hale B, Gauld R. Social inclusion through ageing-in-place with care? Ageing Soc. 2012; 32: 361-78. https://doi.org/10 $.1017 / \mathrm{S} 0144686 \mathrm{X} 11000341$
[29] Board M, McCormack B. Exploring the meaning of home and its implications for the care of older people. J Clin Nurs. 2018; 27: 3070-80. PMid: 29679459. https://doi.org/10.1111/jocn. 14495

[30] Rubinstein R, Parmalee P. Attachment to Place and the Representation of the Life Course by the Elderly. In: ed. By Irwin Altman and Setha M. Low. New York: Springer. In: Altman I, Low S, editors. Place Attach. New York: Springer; 1992.

[31] Larsson Å, Haglund L, Hagberg JE. Doing everyday life-experiences of the oldest old. Scand J Occup Ther. 2009; 16: 99-109. PMid: 18821446. https://doi.org/10.1080/11038120802409762

[32] Penney L. The uncertain bodies and spaces of aging in place. Anthropol Aging Q 2013; 34: 113-25. https://doi.org/10.5195/aa .2013 .12

[33] Aged Care Financial Performance Survey Sector Report 2019.

[34] Rowles GD. Prisoners of space? Exploring the geographical experience of older people. Boulder: Westview press; 2018.

[35] Odzakovic E, Hellström I, Ward R, et al. Overjoyed that I can go outside: Using walking interviews to learn about the lived experience and meaning of neighbourhood for people living with dementia. Dementia. 2018; 1471301218817453. PMid: 30541394. https://doi.org/10.1177/1471301218817453

[36] Battersby A, Phillips L. In the End It All Makes Sense: Meaning in Life at Either End of the Adult Lifespan. Int J Aging Hum Dev. 2016; 83: 184-204. PMid: 27166366. https://doi.org/10.1177/00 91415016647731

[37] Gill L, Bradley SL, Cameron ID, et al. How do clients in Australia experience Consumer Directed Care? BMC Geriatr. 2018; 18: 148 PMid: 29940873. https://doi.org/10.1186/s12877-018-0 838-8

[38] Day J, Thorington Taylor AC, Hunter S, et al. Experiences of older people following the introduction of consumer-directed care to home care packages: A qualitative descriptive study. Australas J Ageing. 2018; 37: 275-82. PMid: 29896917. https://doi.org/10.1111/ ajag. 12553

[39] Ottmann G, Mohebbi M. Self-directed community services for older Australians: a stepped capacity-building approach. Health Soc Care Community. 2014; 22: 598-611. PMid: 24889885. https: //doi.org/10.1111/hsc.12111 